\title{
Association between diabetes and vestibular dysfunction: an integrative review
}

\author{
Roberta Carneiro de Toledo ${ }^{1}$ \\ https://orcid.org/0000-0002-7785-8158 \\ Cibelle Kayenne Martins Roberto Formiga ${ }^{1}$ \\ https://orcid.org/0000-0002-5837-297X
}

Flávio Monteiro Ayres ${ }^{1}$

https://orcid.org/0000-0003-1170-6933

Universidade Estadual de Goiás - UEG, Goiânia, Goiás, Brasil.

Research support source: Coordenação de Aperfeiçoamento de Pessoal de Nível Superior - CAPES

Conflict of interests: Nonexistent

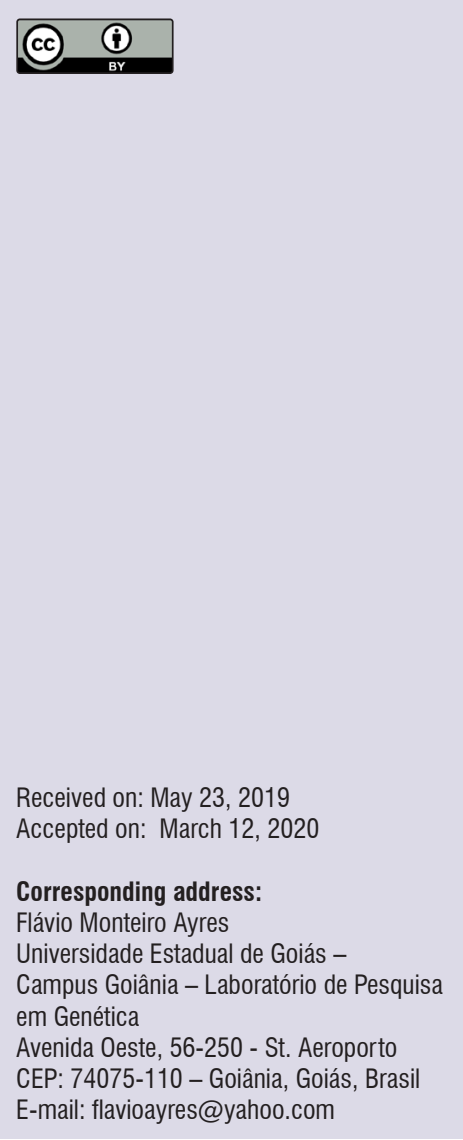

\section{ABSTRACT}

Purpose: to identify, in the literature, the factors associated with the development of vestibular dysfunctions in individuals with type 2 diabetes mellitus (DM2).

Methods: an integrative review of the literature, whose survey was conducted in the databases ISI, SciELO, LILACS and PubMed, using the following descriptors: "type 2 diabetes mellitus", "vertigo", "dizziness", and "vestibular diseases". Articles published in the last 10 years that answered the research question ("What factors are associated with the development of vestibular disorders in individuals with DM2?") were included in the study.

Results: the search returned 426 articles, 10 of which met the eligibility criteria. Most of the participants of the selected studies who had vestibular dysfunctions were women over 40 years old and had more than one comorbidity related to DM2, the main one being the systemic arterial hypertension (SAH). According to the literature, the physiology of the inner ear allows small glucose alterations to influence its normal functioning, which makes diabetic individuals more susceptible to developing vestibular dysfunctions.

Conclusion: according to this study, DM2 can trigger or contribute to the manifestation of vestibular dysfunction, whose main associated factors are advanced age, female gender, and various comorbidities, as dyslipidemia, SAH and metabolic syndrome.

Keywords: Dizziness; Vertigo; Diabetes Mellitus; Labyrinth Diseases 


\section{INTRODUCTION}

Diabetes mellitus is one of the most prevalent chronic diseases in the population worldwide, with Brazil as the fourth country most affected by it. According to the International Diabetes Federation, in 2017 approximately 425 million people were diagnosed with diabetes, and it is believed that until 2045 there will be about 629 million diabetics in the world ${ }^{1}$.

Type 2 diabetes mellitus (DM2) corresponds to $90 \%$ of the cases and occurs more frequently in obese people over 40 years old. It is characterized as a heterogeneous syndrome resulting from the deficiency in insulin secretion or the interference in its function, and its most common clinical manifestation is chronic hyperglycemia ${ }^{2}$. The cause of DM2 has not been fully clarified yet; however, some factors can increase the possibility that an individual will develop the disease, such as environmental, genetic and behavioral factors. It is estimated that $80 \%$ of the people with DM2 are overweight and do not practice physical exercise ${ }^{3}$.

The presence of DM2 has been increasingly significant in the field of otoneurology due to its high prevalence in patients with labyrinth diseases. Among the most recurrent symptoms in these patients, there is dizziness, which has been described as a new complication of diabetes, besides being a potentializing risk factor for falls ${ }^{4,5}$. Dizziness is characterized as the symptom of disturbed or impaired spatial orientation'. Middle-aged and older adults with DM2 who had dysfunctions in other organs and systems, as cardiovascular alterations, peripheral neuropathies, and vestibular symptoms, also present a greater risk of postural imbalance, making them more fragile and vulnerable to falls ${ }^{7-9}$.

The presence of peripheral neuropathies constitutes an important risk factor for falls in diabetic individuals. Diabetic neuropathy originates in microvascular complications that affect the peripheral sensory and motor nerves, and its prevalence is higher than $50 \%$ in patients diagnosed with the disease ${ }^{9,10}$.

Peripheral vestibular alterations are strongly influenced by insulin and glycemic levels circulating in the blood. The higher these levels, the greater is the patient's susceptibility in developing dysfunction of vestibular origin, as benign paroxysmal positional vertigo (BPPV), endolymphatic hydrops, and Ménière's disease ${ }^{8,9}$.

The analysis of vestibular dysfunctions must consider all the clinical variables that can be altered, making it necessary to understand the association of dizziness-triggering alterations in multiple organs and systems, in order to properly approach the diabetic patient. New clarifications about the existing associations between DM2 and vestibular alterations are needed. Such elucidations will contribute to a more effective clinical approach, favoring this population from prevention to intervention. Thus, this study aimed at identifying, in the literature, the factors associated with the development of vestibular dysfunctions in individuals presented with DM2.

\section{METHODS}

This is an integrative literature review, conducted in six different stages, namely: identification of the theme; definition of the research question; establishment of the study's inclusion and exclusion criteria; definition of the information to be extracted from the studies selected, and categorization of the studies; evaluation of the studies included in the integrative review; interpretation of the results and presentation of the review/synthesis of knowledge. The survey took place from July to August 2019.

The research was guided by the following question: What factors are associated with the development of vestibular dysfunctions in individuals with DM2? The articles were surveyed in the ISI Web of Science, SciELO, LILACS and PubMed databases, with the following terms: "type 2 diabetes mellitus", "vertigo", "dizziness", and "vestibular diseases", according to the Health Sciences Descriptors (DeCS), in these combinations: "type 2 diabetes mellitus AND vertigo", "type 2 diabetes mellitus AND dizziness", "type 2 diabetes mellitus AND vestibular diseases".

The inclusion criteria adopted for the research were: primary data, cross-sectional articles, published between 2009 and the first semester of 2019, in either English, Portuguese or Spanish. Articles describing type 1 diabetes mellitus or central vestibular dysfunctions, as well as editorials, theoretical reflections, all sorts of reviews, experience reports, dissertations, monographs, theses, and abstracts in annals of events were excluded from the research.

All the papers were analyzed and classified according to the levels of evidence employed by ASHA ${ }^{11}$ in 2004, adapted from the Scottish Intercollegiate Guideline. The studies were analyzed based on eight scientific study quality indicators, namely: Well-designed metaanalysis of more than one randomized controlled trial (la); well-designed randomized controlled study (Ila); well-designed nonrandomized controlled study (Ib); 
well-designed quasi-experimental study (IIb); welldesigned nonexperimental study (III); report from a specialized committee, consensus conference, clinical experience of respected authorities (IV).

\section{LITERATURE REVIEW}

As the databases were surveyed, 426 articles related to the theme were identified (Figure 1). Of these, 356 were excluded based on their title or because they did not answer the research problem in question; 42, after the abstracts had been read; 7 , because they were repeated in the databases; and 12, after the articles had been fully read. The sample was thus composed of 10 articles. The prevailing language was English, followed by Spanish. No studies in Portuguese were identified. The studies included in the research were described in Table 1, by author/year of publication, objectives of the study, number of the sample, and main results. The otoneurological dysfunctions presented in the selected studies and the comorbidities associated with DM2 were described in Table 2.

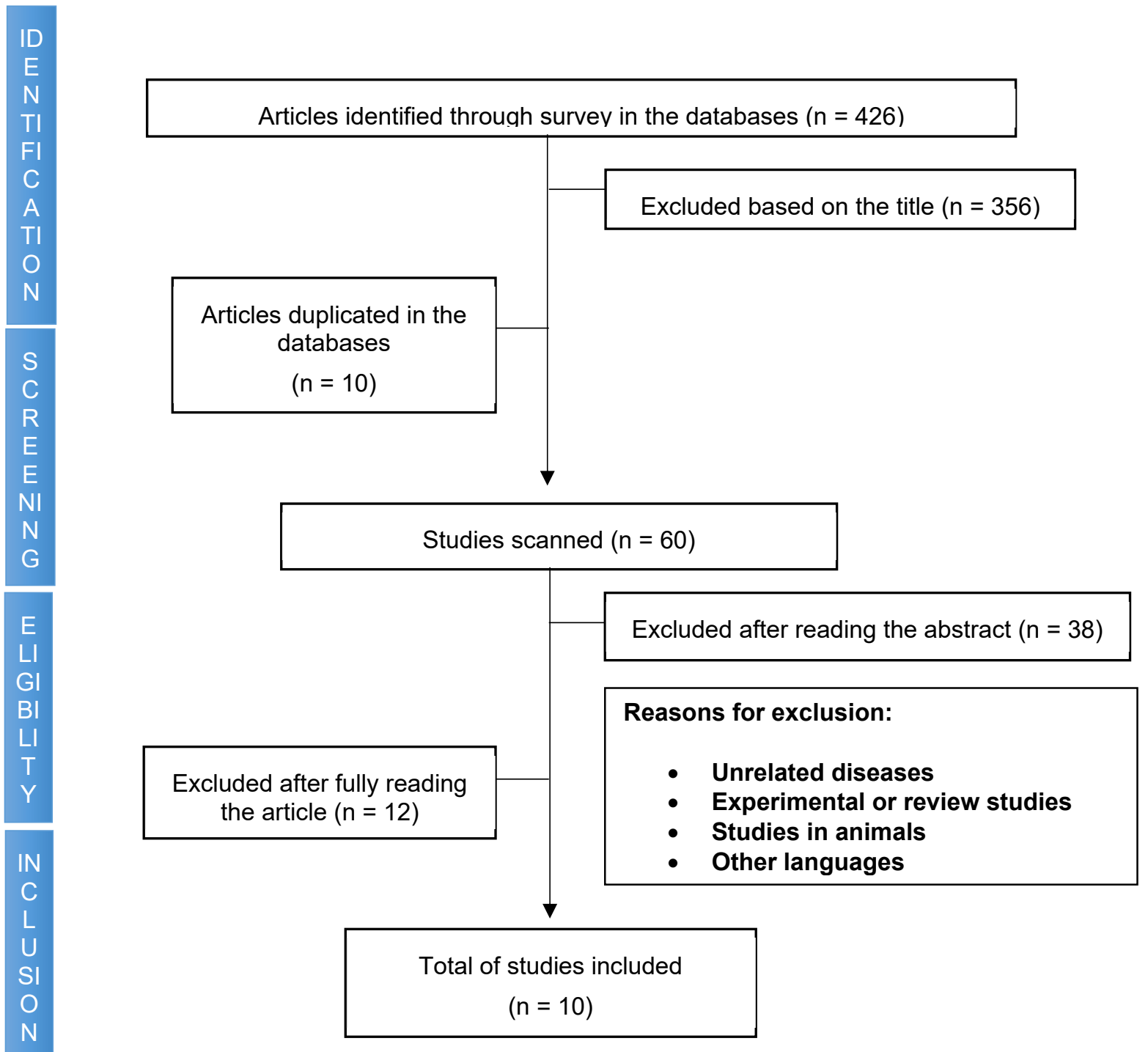

Source: the author

Legend: $n=$ number of articles.

Figure 1. Flowchart of the selection of articles in the databases. 
Table 1. Listing of the papers analyzed

\begin{tabular}{|c|c|c|c|c|c|}
\hline Authors/Year & $\begin{array}{l}\text { Methodological } \\
\text { Design }\end{array}$ & Purpose & Sample & Main Results & $\begin{array}{c}\text { Level of } \\
\text { Evidence } \\
\text { (ASHA, } \\
\text { 2004) }\end{array}$ \\
\hline
\end{tabular}

$\begin{array}{ccl}\text { Chávez- } & \text { To determine the type and degree } \\ \text { Delgado et } & \text { Cross-sectional } & \begin{array}{l}\text { of cochleovestibular dysfunction in } \\ \text { patients with DM2, SAH and dyslipi- } \\ \text { demia with auditory and/or vestibular } \\ \text { al., 2012 }\end{array} \\ \text { symptoms. }\end{array}$

To determine the prevalence of meYamanaka et Case-control tabolic syndrome and the clinical al., 2013 2 study characteristics associated with metabolic syndrome and vertigo.

To examine the relationship between D'Silva et al., Retrospective diabetes and BPPV along with known $2015^{14} \quad$ study variables, as age, gender, and hypertension.

To evaluate the degree of association between diabetes and otoconial dysfunctions. To evaluate the asso-

Ward et al., Prospective study ciation of microvascular complica$2015^{15}$ tions with the presence of vestibular dysfunction in older adults with diabetes.

To describe the symptoms of the in-

Albernaz, Retrospective ner ear metabolic disorders, as well $2016^{16} \quad$ study as the examinations necessary to establish diagnoses.

To analyze the otolith function in people with diabetes and concomitant

D'Silva et al., Cross-sectional
BPPV; and, examine the relationships $2017^{17} \quad$ study between the VEMP variables and the diabetes-related variables.

To evaluate the function of the utricle Jáuregui- Cross-sectional and horizontal semicircular canals Renaud et al., Cross-sectional in patients with DM2, with/without a $2017^{18} \quad$ study history of falls, who received primary care.

D'Silva et al., Case-control To examine postural oscillation in study people with DM2 who present untreated symptomatic BPPV.

To compare the prevalence and the Bepari et al., Case-control association of metabolic disorders $2018^{20} \quad$ study in cases of vertigo with a control group.

To evaluate and find the proportion of patients with DM2 with sensorineural Naik e Tilloo, Cross-sectional hearing loss and vestibular dysfunc$2019^{21} \quad$ study tion, as well as the association with glycemic control.
Age, duration, and extent of polygenic inheritance 385 contribute to the occurrence of cochleovestibular dysfunction.

Metabolic syndrome occurred more frequently in males. Moreover, among the vestibulopathies analyzed, the most recurrent in men was the vertebral-basilar insufficiency. Thus, metabolic syndrome can be associated with the occurrence of vertigo in men.

The study demonstrates that SAH is the mediating 3933 factor that contributes to the increase in BPPV prevalence in diabetic individuals.

The adults with DM2 presented worse performances in the vestibular function test regarding the

50 function of the semicircular canals and the otoconia in comparison with the non-diabetic group, causing various vestibular complications.

Due to the physiology of the inner ear, the auditory and vestibular symptoms usually occur before other 376 manifestations of metabolic alterations, potentially favoring an early diagnosis of hyperinsulinemia, intestinal sugar malabsorption, or diabetes.

Both individuals with BPPV and those with diabetes presented otolith dysfunction, indicating that BPPV and DM can independently affect the utricular function.

Patients with DM2 that did not seek care due to sensorial or balance decline presented impaired utricular function, even in the absence of semicircular canal dysfunction or history of falls. In addition, the occurrence of falls may not be independently related to the vestibular function.

Individuals with BPPV, with and without DM2, presented greater postural oscillation when standing with eyes closed and standing in comparison with people with DM and healthy people. The presence of peripheral neuropathy was also described as contributing to postural instability.

The individuals with vertigo presented high thyroid and circulating lipids levels. Such factors indicate the importance of dietary control and hormonal therapy in vertiginous patients.

There is a significant association between DM2, auditory sensorial loss, and vestibular dysfunction, especially with the aggravation of the glycemic control. 100 Controlling diabetes would avoid the complications associated with the vestibular system, ensuring these patients a better lifestyle.
III

Ilb

Source: the author.

Legend: DM2 (type 2 diabetes mellitus); BPPV (benign paroxysmal positional vertigo) 
Table 2. Description of the otoneurological dysfunctions presented in the studies selected and the comorbidities associated with DM2.

\begin{tabular}{|c|c|c|}
\hline Authors/Year & Vestibular Dysfunction & Comorbidities \\
\hline Chávez-Delgado et al., $2012^{12}$ & Cochleovestibular dysfunction & $\begin{array}{c}\text { SAH, dyslipidemia, overweight, sedentarism, } \\
\text { smoking }\end{array}$ \\
\hline Yamanaka et al., $2013^{13}$ & $\begin{array}{c}\text { Ménière's disease, BPPV, and vertebral-basilar } \\
\text { insufficiency }\end{array}$ & MS \\
\hline D'Silva et al., $2015^{14}$ & BPPV and Ménière's disease & $\mathrm{SAH}$ \\
\hline Ward et al., $2015^{15}$ & Utricular dysfunction & Neuropathy and retinopathy \\
\hline Albernaz, $2016^{16}$ & Vestibular and cochlear dysfunctions & Hypoglycemia and hyperglycemia \\
\hline D'Silva et al., $2017^{17}$ & BPPV & SAH and peripheral neuropathy \\
\hline $\begin{array}{l}\text { Jáuregui-Renaud et al., } \\
2017^{18}\end{array}$ & Dizziness and vertigo & peripheral neuropathy, retinopathy, and SAH \\
\hline D'Silva et al., $2017^{19}$ & BPPV & Obesity and peripheral neuropathy \\
\hline Bepari et al., $2018^{20}$ & Dizziness & $\begin{array}{l}\text { High LDL and thyroid-stimulating hormone levels } \\
\text { associated with MS }\end{array}$ \\
\hline Naik e Tilloo, $2019^{21}$ & BPPV and unilateral vestibular dysfunction & $\begin{array}{c}\text { Sensorineural hearing loss and uncontrolled } \\
\text { hyperglycemia }\end{array}$ \\
\hline
\end{tabular}

Source: the author

Legend: DM2 (type 2 diabetes mellitus); BPPV (benign paroxysmal positional vertigo); SAH (systemic arterial hypertension), LDL (low-density lipids); MS (metabolic syndrome)

All the articles included in the study presented a mean age of over 40 years. Such a result agrees with the literature, which describes the prevalence of DM2 after 40 years $\mathrm{old}^{2}$. The females were prevalent in nine of the ten articles included. The high prevalence of females can be attributed both to hormonal cycle variations and women seeking health services more often. Moreover, individuals with DM2 presenting vestibular dysfunctions had more than one clinical alteration associated with it, of which the main ones are systemic arterial hypertension (SAH), metabolic syndrome (MS), retinopathy, and peripheral neuropathy ${ }^{12,14,15,19}$. In two studies analyzed ${ }^{13,19}$, the levels of dizziness and the number of clinical alterations were directly proportional to age.

Four other studies ${ }^{12,14,15,18}$ identified $\mathrm{SAH}$ as one of the risk factors for the development of vestibular dysfunction associated with DM2, of which BPPV is the main one. The vascular effects of SAH and diabetes can lead to tissue hypoxia and cochleovestibular degeneration, causing increased stiffness of the arterial walls. Increased arterial pressure compromises capillary blood flow and, consequently, the transportation of oxygen. Thus, nutrients are not sufficiently furnished to the inner ear structures ${ }^{15,22,23}$.

The influence of the MS on the vestibular system as a factor associated with irreversible cochleovestibular deterioration was investigated in three studies ${ }^{12,13,20}$. The term MS refers to a set of risk factors that increase the possibility of a person developing cerebrovascular diseases and diabetes. Diabetes is associated with microvascular modifications, leading to alterations in inner ear blood flow, with symptoms of disturbance of body balance. The occurrence of hyperglycemia generates an increase in inflammatory mediators and protein glycation, causing these to be functionally inactive, in addition to auto-oxidation of glucose particles, leading to the formation of free radicals; these cause the destruction and dysfunction of cells, as the pancreatic $\beta$-cells, which produce insulin. This connection between the inflammation and physiopathology of the inner ear vessels interfere with the local blood flow. Due to the lack of collateral circulation, any type of local arterial occlusion can cause an ischemic event, which brings about vestibular dysfunctions in the patient ${ }^{13,24}$.

Bepari et al. ${ }^{20}$, when evaluating the hemograms of a group of diabetic patients, identified high values of thyroid-stimulating hormone (T3, T4 and TG), besides the increase in low-density lipids (LDL). The increase in serum cholesterol is one of the risk factors for the development of atherosclerosis, which also has a role in the vestibulocochlear vessels, especially in individuals over 40 years old. Hence, the importance of multidisciplinary clinical follow-up is highlighted, including hormonal and dietary therapy ${ }^{20}$.

Six articles report on the influence of hyperglycemia on the functioning of the vestibular system ${ }^{13,15-18,21}$. 
Endolymphatic hydrops was prevalent in $45 \%$ of the individuals with MS associated with dyslipidemia. The inner ears are very sensitive organs and are often the first ones to present signs of disorder in metabolism. Since glucose is one of the most efficient substrates for the maintenance of the endolymphatic potential, its excess generates a hydro-electrolytic imbalance that directly affects the transportation of sodium and potassium ions. Ionic imbalance displaces potassium from the endolymph to the perilymph, and sodium in the opposite direction, causing an accumulation of water in the internal compartments. Such alteration leads to what is called endolymphatic hydrops ${ }^{16,25}$. Hypoglycemia can also be associated with dizziness, as described in a study ${ }^{16}$. The inner ear physiology requires sharp metabolic activity. Glucose unavailability, as occurs in hypoglycemia, causes functional modifications in the inner ear, resulting in symptoms of vestibular disturbance.

The individuals with diabetes are prone to developing complications, as peripheral neuropathy and retinopathy, which are associated with increased risk of falls ${ }^{26-28}$. This fact can be explained by the excessive production of free radicals in the neural cells and structures resulting from the high levels of circulating glycemia, which brings about diminished fibrinolytic activity and membrane repolarization. These alterations cause irreversible damage to the protein constitution of the myelin sheath, responsible for the demyelination of the peripheral nerves, leading to the development of neuropathies and retinopathies. Since the static and dynamic balance results from the harmonic interaction between the visual, somatosensorial, musculoskeletal and vestibular systems, the microvascular complications in these systems interfere with the adjustments necessary to maintain body balance. Falls stand out among the main concerns related to imbalance, due to their great influence on the affected individual's general health9,28,29.

BPPV was the most recurrent vestibular dysfunction in the studies analyzed ${ }^{13,14,17,19}$ and it has been more frequently described in diabetic individuals. These results support the hypothesis of a vascular role in the etiopathogenesis and recurrence of BPPV ${ }^{14,17}$, which results from an abnormal stimulus of the cupula of any semicircular canal when the head position is changed. The movement of the otoconia in the macula inside the semicircular canals abnormally stimulates the cupula, generating nervous impulses ${ }^{30,31}$. DM2 is associated with the vascular damages in the inner ear, possible labyrinthine ischemia, favoring otoconial detachment, leading to the occurrence of BPPV. The affection of other vascular diseases, as SAH and hyperlipidemia, causes a further reduction or total interruption of local blood flow ${ }^{12,30}$.

Five of the articles selected in this study were classified as level of evidence III, and five, as level of evidence Ilb, according to ASHA ${ }^{11}$. The design of the papers found was considered of medium and low scientific evidence, although it should be considered that nonexperimental studies also have great relevance to better understand a specific theme. In most of the studies included, the participants presented other diseases associated with DM2, which makes it even more difficult to outline the repercussions of diabetes on the vestibular system, as different metabolic and vascular disorders, either associated or not, are causal agents. Medications, hormonal dysfunctions, inadequate eating habits, life habits, sedentarism and stress can equally aggravate or trigger labyrinthopathies ${ }^{31,32}$. Further long-term follow-up studies of individuals with DM2 presenting vestibular repercussions are made necessary in order to better outline the complications resulting from diabetes mellitus. Furthermore, it is of utmost importance that each patient be periodically and multidisciplinarily followed up, for their general health and quality of life to be improved.

\section{CONCLUSION}

This study shows that DM2 can trigger a vestibular dysfunction or contribute to its manifestation. In the literature, advanced age, female gender, and comorbidities such as dyslipidemia, systemic arterial hypertension, and metabolic syndrome were identified as the main factors associated with the development of vestibulopathies in type 2 diabetic patients.

\section{REFERENCES}

1. Federação Internacional de Diabetes. Citado em 20 de agosto de 2019. Disponível em: www.idf.org/ metabolic_syndrome, website of the International Diabetes Federation.

2. Sociedade Brasileira de Diabetes. Diretrizes da Sociedade Brasileira de Diabetes (2017-2018). São Paulo: Editora Clannad, 2017.

3. Coqueiro M, Oliveira AE, Figueiredo TAM. Diabetes Mellitus in the printed media: an analysis of the articles in the newspapers of Espírito Santo, Brazil. Saúde Debate. 2019;43(121):530-42. 
4. Ivers RQ, Cumming RG, Mitchell P, Peduto AJ. Diabetes and risk of fracture: the Blue Mountains Eye Study. Diabetes Care. 2001;24(7):1198-203.

5. Bisdorf A, Brevern MV, Lempert T, NewmanToker DE. Classification of vestibular symptoms: Towards an international classification of vestibular disorders. JVR. 2009;(19):1-13.

6. Borges MGS, Rocha LR, Couto EAB, Mancini PC. Comparison of balance, depression, and cognition in institutionalized and non-institutionalized elderly individuals. Rev. CEFAC. 2015;15(5):1073-9.

7. Coelho AR, Andre APR, Perobellib JLL, Sonobeb LS, Abreu DCC. Immediate effects of an anchor system on the stability limit of individuals with chronic dizziness of peripheral vestibular origin. Braz J Otorhinolaryng. 2017;83(1):3-9.

8. Silva EMT, Lima Filho BF, Mantello EB, Sousa AGP, Diniz Júnior J, Gazzola JM. Diseases and symptoms associated with changes in postural balance in diabetics: an integrating literature review. Rev. CEFAC. 2019;21(6)1-8.

9. Gioacchinni FM, Albera R, Scarpa A, Cassandro C. Hyperglycemia and diabetes mellitus are related to vestibular organs dysfunction: truth or suggestion? A literature review. Acta Diabetol. 2018;55(12):1201-7.

10. Moreira do Nascimento OJ, Castelo C, Pupe B, Boiteux E, Cavalcanti U. Diabetic neuropathy. Rev. dor. 2016;17(Suppl 1):46-51.

11. Mullen R. The state of the evidence: ASHA develops levels of evidence for communication sciences and disorders. 10 de julho de 2019. The ASHA Leader, pp. 8-9, 24-25. Disponível em: http://www.asha.org/ publications/leader/2007/070306/f070306b.htm.

12. Chávez-Delgado ME, Vázquez-Granados I, Rosales-Cortés M, Velasco-Rodríguez V. Cochleovestibular dysfunction in patients with diabetes mellitus, hypertension, and dyslipidemia. Acta Otorrinolaringol Esp. 2012;63(2):93-101.

13. Yamanaka T, Fukuda T, Shirota S, Sawai Y, Murai $\mathrm{T}$, Fujita N. The prevalence and characteristics of Metabolic Syndrome in patients with vertigo. Plos One. 2013;8(12):1-5.

14. D'Silva LJ, Staeckerb H, Linb J, Sykesb KJ, Phadnisc MA, McMahond TM et al. Retrospective data suggests that the higher prevalence of benign paroxysmal positional vertigo in individuals with type 2 diabetes is mediated by hypertension. JVR. 2015;25(5):233-9.
15. Ward BK, Wenzel A, Kalyani RR, Agrawal Y, Feng $A L$, Polydefkis $M$ et al. Characterization of vestibulopathy in individuals with type 2 diabetes mellitus. Otolaryngol Head Neck Surg. 2015;153(1):112-8.

16. Albernaz PLM. Hearing loss, dizziness, and carbohydrate metabolism. Int Arch Otorhinolaryngol. 2016;20(3):261-70.

17. D’Silva LJ, Staecker H, Lin J, Maddux C, Ferraro J, Dai $\mathrm{H}$ et al. Otolith dysfunction in persons with both diabetes and benign paroxysmal positional vertigo. Otology\&Neurotology. 2017;38(3):379-85.

18. Jaugueri-Renaud K, Aranda-Moreno C, HerreraRangel A. Utricular hypofunction in patients with type 2 diabetes mellitus. Acta Otorhinolaryngol Ital. 2017;37(5):430-5.

19. D'Silva LJ, Whitney SL, Santos M, Dai H, Kluding PM. The impact of diabetes on mobility, balance, and recovery after repositioning maneuvers in individuals with benign paroxysmal positional vertigo. J Diabet Complicat. 2017;31(6):976-82.

20. Bepari K, Panditray S, Palai S, Jyotishi B. A comparative study of metabolic disorders in vertigo. J Evolution Med DentSci. 2018;7(2):188-93.

21. Naik CS, Tiloo R. Vestibular dysfunction and glycemic control in Diabetes Mellitus: Is there a correlation? Indian $\mathrm{J}$ of Otology. 2019;24(3):199-203.

22. Marchiori LLM, Melo JJ, Possette FLF, Correa $\mathrm{AL}$. Comparison of frequency of vertigo in elderly with and without arterial hypertension. Arq Int Otorrinolaringol. 2010;14(4):456-60.

23. Ribeiro WA, Mariano ES, Cirino HP, Teixeira JM, Martins LM, Andrade M. Health education for patients with diabetes mellitus and hypertension in family health strategy. Rev Pró-Univer SUS. 2017;8(2):110-4.

24. Lee $\mathrm{H}$. Recent advances in acute hearing loss due to posterior circulation ischemic stroke. J NeurolSci. 2014;38(8):23-9.

25. Malucelli DA, Malucelli FJ, Fonseca VR, Zeigeboim B, Ribas A, Trotta FD et al. Hearingloss prevalence in patients with diabetes mellitus type 1 . Braz J Otorhinolaryngol. 2012;78(3):105-15.

26. Kammerlind ASC, Bravell ME, Fransson El. Prevalence of and factors related to mild and substantial dizziness in communitydwelling older adults: a cross-sectional study. BMC Geriatrics. 2016;16(1):151-9. 
27. Hateren KJV, Kleefstra N, Blanker MH, UbinkVeltmaat LJ, Groenier KH, Houweling ST et al. Orthostatic hypotension, diabetes, and falling in older patients: a cross-sectional study. $\mathrm{Br} \mathrm{J}$ Gen Pract. 2012;62(603):696-702.

28. Kamgar M, Nobakhthaghighi N, Shamshirsaz AA, Estacio RO, McFann KK, Schrier RW. Impaired fibrinolytic activity in type II diabetes: correlation with urinary albumin excretion and progression of renal disease. Kidney Int. 2006;69(10):1899-903.

29. Deli G, Bosnyak E, Pusch G, Komoly S, Feher G. Diabeticneuropathies: diagnosis and management. Neuroendocrinology. 2013;98(4):267-80.

30. Cohen HS, Kimball KT, Stewart MG. Benign paroxysmal positional vertigo and comorbid conditions. ORL J Otorhinolaryngol Relat Spec. 2004;66(1):11-5.

31. Von Brevern M, Bertholon P, Brandt $T$, Fife $T$, Imai T, Nuti D. Benign paroxysmal positional vertigo: Diagnostic Criteria Consensus Document of the Committee for the Classification of Vestibular Disorders of the Bárány Society. Acta Otorrinolaringol Esp. 2017;68(6):349-60.

32. Ganança FF. Elderly falls associated with benign paroxysmal positional vertigo. Braz J Otorhinolaryngol. 2010;76(1):113-20. 